\title{
$6 \beta$-Hydroxytestosterone, a metabolite of testosterone generated by CYP1B1, contributes to vascular changes in angiotensin II-induced hypertension in male mice
}

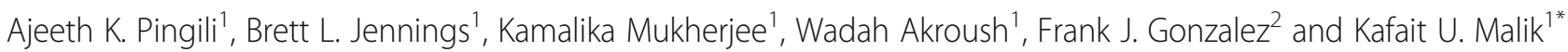

\begin{abstract}
Background: Previously, we showed that $6 \beta$-hydroxytestosterone (6ß-OHT), a cytochrome P450 1B1 (CYP1B1)derived metabolite of testosterone, contributes to angiotensin II (Ang II)-induced hypertension in male mice. This study was conducted to test the hypothesis that $6 \beta-\mathrm{OHT}$ contributes to increased vascular reactivity, endothelial dysfunction, vascular hypertrophy, and reactive oxygen species production associated with Ang II-induced hypertension.
\end{abstract}

Methods: Eight- to 10-week-old intact or castrated C57BL/6 J (Cyp $1 b 1^{+/+}$and Cyp $\left.1 b 1^{-/-}\right)$mice were anesthetized for implantation of a micro-osmotic pump which delivered Ang II (700 ng/ $/ \mathrm{kg} /$ day) or saline for 14 days. Mice were injected with $6 \beta-\mathrm{OHT}(15 \mu \mathrm{g} / \mathrm{g}$ b.w every third day), flutamide ( $8 \mathrm{mg} / \mathrm{kg}$ every day), or its vehicle. Blood pressure was measured via tail-cuff. Vascular reactivity, endothelial-dependent and endothelial-independent vasodilation, media to lumen ratio, fibrosis by collagen deposition, and reactive oxygen species production by dihydroethidium staining were determined in the isolated thoracic aorta.

Results: The response of thoracic aorta to phenylephrine and endothelin-1 was increased in Ang Il-infused Cyp $1 b 1^{+/+}$mice compared to intact Cyp $1 b 1^{-/-}$or castrated Cyp $1 b 1^{+/+}$and Cyp $1 b 1^{-/-}$mice; these effects of Ang II were restored by treatment with $6 \beta-\mathrm{OHT}$. Ang II infusion caused endothelial dysfunction, as indicated by decreased relaxation of the aorta to acetylcholine in $C y p 1 b 1^{+/+}$but not Cyp $1 b 1^{-/-}$or castrated $C y p 1 b 1^{+/+}$and $C y p 1 b 1^{-/-}$mice. $6 \beta-O H T$ did not alter Ang II-induced endothelial dysfunction in Cyp $1 b 1^{+/+}$mice but restored it in $C y p 1 b 1^{-/-}$or castrated $\mathrm{Cyp}_{\mathrm{Bb}} \mathrm{1}^{+/+}$and $\mathrm{Cyp} 1 \mathrm{~b} 1^{-/-}$mice. Ang II infusion increased media to lumen ratio and caused fibrosis and reactive oxygen species production in the aorta of $C y p 1 b 1^{+/+}$mice. These effects were minimized in the aorta of

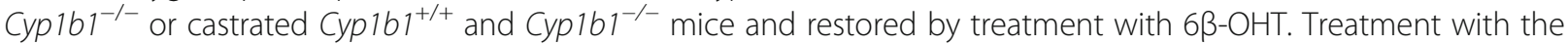
androgen receptor antagonist flutamide reduced blood pressure and vascular hypertrophy in castrated Ang IIinfused mice injected with $6 \beta-\mathrm{OHT}$.

(Continued on next page)

\footnotetext{
* Correspondence: kmalik@uthsc.edu

'Department of Pharmacology, College of Medicine, University of Tennessee

Health Science Center, 71 S. Manassas TSRB, Memphis, TN 38103, USA

Full list of author information is available at the end of the article
}

(c) The Author(s). 2020 Open Access This article is distributed under the terms of the Creative Commons Attribution 4.0 International License (http://creativecommons.org/licenses/by/4.0/), which permits unrestricted use, distribution, and reproduction in any medium, provided you give appropriate credit to the original author(s) and the source, provide a link to the Creative Commons license, and indicate if changes were made. The Creative Commons Public Domain Dedication waiver (http://creativecommons.org/publicdomain/zero/1.0/) applies to the data made available in this article, unless otherwise stated. 
(Continued from previous page)

Conclusions: $6 \beta-\mathrm{OHT}$ is required for the action of Ang II to increase vascular reactivity and cause endothelial dysfunction, hypertrophy, and increase in oxygen radical production. The effect of $6 \beta-O H T$ in mediating Ang $\|-$ induced hypertension and associated hypertrophy is dependent on the androgen receptor. Therefore, CYP1B1 could serve as a novel target for the development of therapeutics to treat vascular changes in hypertensive males.

Keywords: Angiotensin II, Hypertension, CYP1B1, Testosterone metabolite 6 $\beta$-hydroxytestosterone, Vascular reactivity, Endothelial dysfunction, Vascular hypertrophy, Fibrosis, Flutamide

\section{Introduction}

Hypertension is the leading cause of cardiovascular diseases, renal dysfunction, and end-organ damage, and biological sex plays a significant role in the pathogenesis of hypertension and associated end-organ damage [1-4]. Sex differences in the development of hypertension and alterations in cardiovascular and renal function have been demonstrated in various experimental models of hypertension, which has been attributed to sex chromosomes and sex hormones [5-9]. Ang II increases blood pressure (BP) to a much higher level in males than in females, and it is reduced by castration in males, but enhanced by ovariectomy in females [10]. Previously, we demonstrated that the protective effect of 17- $\beta$ estradiol against Ang II-induced hypertension and associated cardiovascular and renal pathophysiological changes are mediated most likely by its metabolite, 2-methoxyestradiol generated by CYP1B1 in female mice [11-13]. However, in contrast, Ang II-induced hypertension and cardiac and renal pathological changes that were minimized in castrated or $C y p 1 b 1^{-/-}$mice were restored by treatment with testosterone-CYP1B1 generated

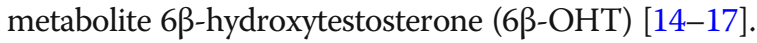

In as much as $6 \beta-\mathrm{OHT}$ treatment alone did not produce any effect, we concluded that it acts as a permissive factor, in that it is required for the expression of these effects of Ang II [16-17]. Since Ang II causes vascular dysfunction, hypertrophy, fibrosis, and reactive oxygen species production (ROS) [18], we hypothesized that $6 \beta$ OHT mediates these vascular effects of Ang II in male mice. To test this hypothesis, we investigated the contribution of $6 \beta-\mathrm{OHT}$ to the effects of Ang II to increase vascular reactivity, endothelial dysfunction, hypertrophy, fibrosis, and ROS production in Ang II-induced hypertension in the thoracic aorta of castrated $C y p 1 b 1^{+/+}$and Cyp $1 \mathrm{bl}^{-/-}$mice that lack endogenous testosterone and $6 \beta-\mathrm{OHT}$.

\section{Materials and methods Materials}

Angiotensin II (Ang II) was purchased from Bachem (Torrance, $\mathrm{CA}$ ), dihydroethidium (DHE) from Invitrogen (Carlsbad, CA), and 6 $\beta$-hydroxytestosterone (6 $\beta$-OHT) from Steraloids (Newport, RI). Phenylephrine, endothelin1 , acetylcholine, the Masson trichrome staining kit, and phosphate-buffered saline were purchased from Sigma (St. Louis, MO).

\section{Animals}

All experiments were carried out according to protocols approved by the University of Tennessee Health Science Center Institutional Animal Care and Use Committee and in accordance with the National Institutes of Health Guide for the Care and Use of Laboratory Animals. C57BL/6J Cyp $1 b 1^{+/+}$male mice were purchased from Jackson Laboratory (Bar Harbor, ME), and Cyp $1 b 1^{-1-}$ male mice from the C57BL/6J background were initially generated at the National Cancer Institute [19], and then bred at the University of Tennessee Health Science Center. The genotype of all $C y p 1 b 1^{+/+}$and $C y p 1 b 1^{-/-}$mice was routinely assessed by polymerase chain reaction (PCR) as described [19]. Eight- to 10-week-old male mice were acclimatized in restrainers for 1 week, and blood pressure was measured 2-3 times via tail-cuff. The animals were then anesthetized with a mixture of ketamine $(87 \mathrm{mg} / \mathrm{kg}$, i.p.) and xylazine $(13 \mathrm{mg} / \mathrm{kg}$, i.p.), and the micro-osmotic pumps (Alzet ${ }^{\oplus}$; model 1002) were implanted subcutaneously to infuse Ang II $(700 \mathrm{ng} / \mathrm{kg} /$ min) or saline (vehicle) for 14 days. BP was measured in the mice that were used to determine the contribution of $6 \beta$-OHT $(15 \mu \mathrm{g} / \mathrm{g}$, i.p. every third day) to Ang IIinduced hypertension and associated cardiac pathogenesis [16]. In the present study, the following groups of these mice were used to assess aortic vascular reactivity, endothelial dysfunction, media to lumen ratio, fibrosis, and reactive oxygen species production:

a) 6ß-OHT: $C y p 1 b 1^{+/+}$and $C y p 1 b 1^{-/-}$mice were infused with either Ang II or vehicle for 14 days and injected with $6 \beta$-OHT $(15 \mu \mathrm{g} / \mathrm{g}$, i.p.) every third day.

b) Castration: Eight-week-old $C y p 1 b 1^{+/+}$and Cyp $1 b 1^{-1-}$ mice were castrated as described [2]. After a 7-day washout period for the depletion of residual testosterone, the mice were divided into two groups and infused with either vehicle or Ang II as described above.

c) Castration+6 $\beta-O H T$ : Eight-week-old Cyp $1 b 1^{+/+}$ and $C y p 1 b 1^{-/-}$mice were castrated and infused 
with either Ang II or vehicle for 14 days and injected with $6 \beta-\mathrm{OHT}$ every third day.

The following additional group of mice was used to perform experiments with the androgen receptor antagonist flutamide and its vehicle:

Castration+6 $3-\mathrm{OHT}+$ Flutamide: Eight-week-old $C y p 1 b 1^{-/-}$ mice were castrated and infused with either Ang II or vehicle for 14 days, and then injected with the androgen receptor antagonist flutamide [9] ( $8 \mathrm{mg} / \mathrm{kg}$ i.p. daily) and $6 \beta$-OHT $15 \mu \mathrm{g} / \mathrm{g}$ i.p. every third day). Systolic blood pressure (SBP) was measured in these mice via tail cuff, and degree of thoracic aorta hypertrophy was determined as described below.

\section{Measurement of vascular reactivity}

Following anesthesia as described above, the thoracic aortae were quickly dissected free, cleaned of surrounding tissue, and approximately $2-\mathrm{mm}$ rings were mounted in a wire myograph system (Danish Myo Technology, Aarhus, Denmark; model 610M). Vascular reactivity was measured as described [11]. Cumulative concentrationresponse curves to phenylephrine (PE) and endothelin-1 (ET-1) of aortic rings were measured as the force of contraction in millinewton. Viability of the thoracic aorta was determined by measuring its contraction in response to $\mathrm{KCl}(60 \mathrm{mM})$ before and after exposure to PE and ET-1.

\section{Endothelium-dependent and endothelium-independent relaxation of the aorta}

Endothelial function was assessed by measuring the magnitude of relaxation by increasing concentrations of acetylcholine $(\mathrm{ACh})$ in the aortic rings pre-constricted maximally with PE $\left(10^{-5} \mathrm{~mol} / \mathrm{L}\right)$ as described [11]. Endothelium-independent vasodilation was studied by constricting the vessels with the concentration of $\mathrm{PE}$ that evoked a maximal response followed by the addition of increasing concentrations of sodium nitroprusside (SNP). Changes in the response of vessels to SNP were measured and presented as a percentage of the PE-induced constriction as described [11].

\section{Measurement of media/lumen ratio}

Following anesthesia, the thoracic aortae were dissected free, cleaned of surrounding tissue, and frozen in optimal cutting temperature (OCT) compound (Sakura Finetek USA Inc., Torrance, CA). Aortic sections $(5 \mu \mathrm{m})$ were stained with hematoxylin and eosin (H\&E). Sections were viewed in a blinded manner using an Olympus $^{\circ}$ inverted system microscope (Olympus America Inc., Melville, NY, model IX50) and photographed using an Olympus ${ }^{\circ}$ digital camera (Olympus America Inc., model DP71). Images were analyzed using ImageJ 1.42.
The media lumen ratio was calculated from the media thickness/lumen diameter $\times 100$.

\section{Measurement of collagen deposition}

The thoracic aortae were dissected and processed as described above. Collagen staining was performed using Masson's trichrome staining as described [16]. The stained sections were viewed in a blinded manner with an Olympus ${ }^{\circ}$ inverted system microscope as described above. Percentage collagen positive area was analyzed using ImageJ 1.42.

\section{Measurement of vascular ROS production}

To measure vascular reactive oxygen species production, $5 \mu \mathrm{m}$ sections of the thoracic aorta were exposed to dihydroethidium (DHE), following the previously described method [11]. Fresh, unfixed aorta samples were placed in optimal cutting temperature (OCT) compound (Sakura Finetek USA Inc., Torrance, CA) and frozen at $-80^{\circ} \mathrm{C}$. Ring segments were cut into $30 \mu \mathrm{m}$ sections using a cryostat (Bright Instrument Company, Huntingdon, Cambridgeshire, England; model OTF) and placed on a glass slide. Sections were incubated in PBS for 30 min at $37^{\circ} \mathrm{C}$, and then DHE $(2 \mu \mathrm{m})$ was topically applied. Coverslips were applied, and the sections were further incubated at $37^{\circ} \mathrm{C}$ in a light-protected humidified chamber for $30 \mathrm{~min}$. Sections were then rinsed in PBS, and fluorescence was detected using a 585-nm filter using an Olympus inverted system microscope (Olympus America Inc.; model DP71). Images were photographed using an Olympus ${ }^{\bullet}$ digital camera (Olympus America Inc., model DP71) and analyzed in a blinded manner using ImageJ 1.42.

\section{Statistical analysis}

Data were analyzed by two-way analysis of variance followed by Tukey's multiple comparisons post hoc test or the Student $t$ test. Data values from the different experiments are expressed as the mean \pm SEM. $P<0.05$ was considered statistically significant.

\section{Results \\ Cyp $1 b 1$ gene disruption or castration in $C y p 1 b 1^{+/+}$and Cyp $1 b 1^{-1-}$ mice reduced aortic responses to vasoconstrictor agents caused by Ang II infusion, which was restored by $6 \beta-\mathrm{OHT}$}

Ang II-induced hypertension was associated with an increased constriction of the isolated thoracic aortic rings (55\% from Cyp $1 \mathrm{b1}^{+/+}$vehicle-treated group) (Fig. 1a) to maximal concentration of phenylephrine (PE) and (83\% from Cyp $1 \mathrm{bl}^{+/+}$vehicle-treated group) to maximal concentration of endothelin-1 (ET-1); these increases were attenuated by Cyp $1 b 1$ gene disruption (24\% for PE, $52 \%$ for ET-1 compared to Cyp $1 b 1^{+/+}$vehicle-treated group), 

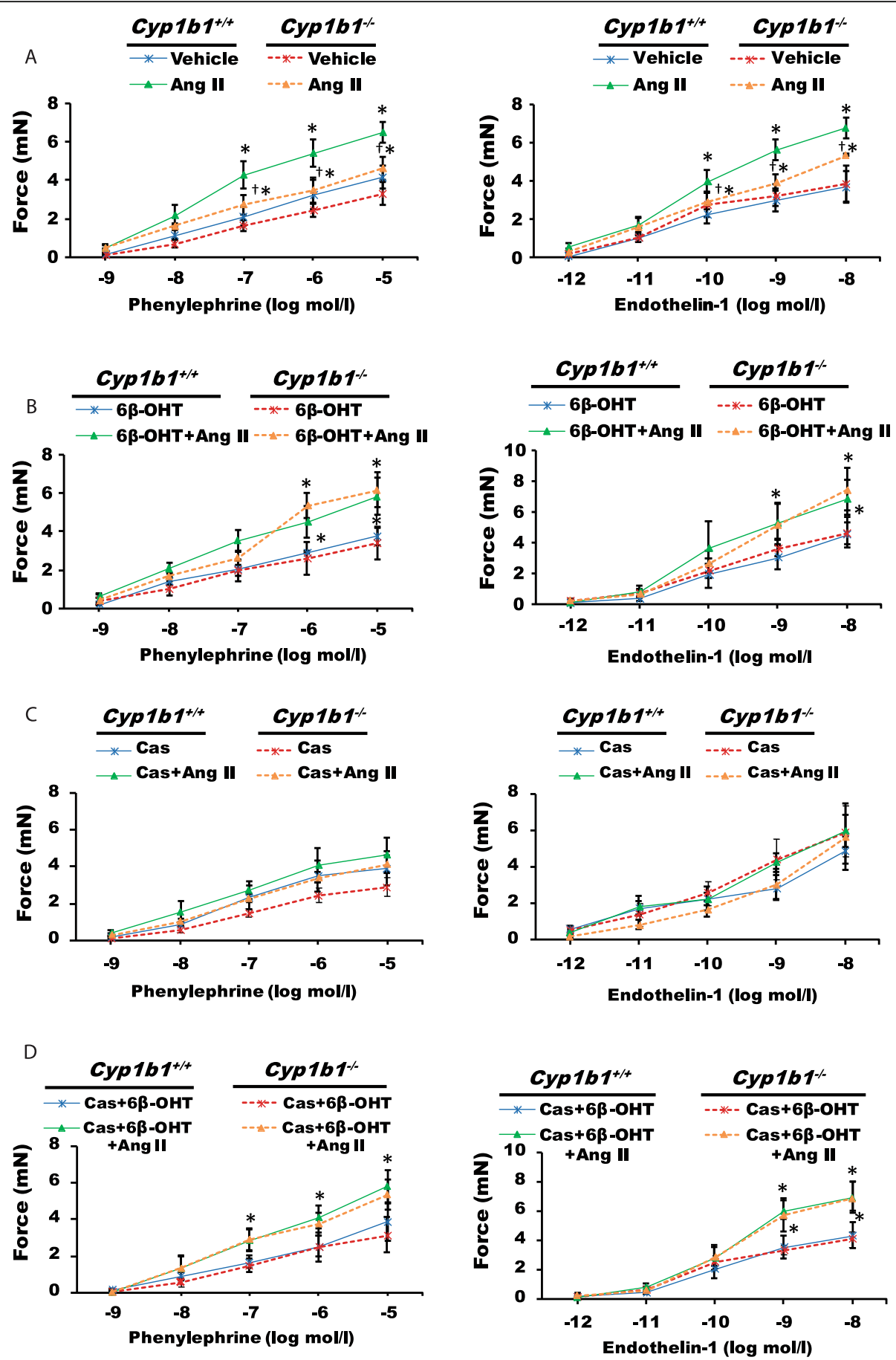

Fig. 1 Cyp 1 bl gene disruption or castration minimized the increase in the aortic response to vasoconstrictor agents associated with angiotensin (Ang) Il-induced hypertension, which was restored by $6 \beta$-hydroxytestosterone (6ß-OHT). Intact or castrated Cyp $1 b 1^{+/+}$and $C y p 1 b 1^{-/-}$mice were infused with either Ang II (700 ng/kg/day) or vehicle for 14 days and given i.p. injections of $6 \beta-O H T(15 \mu \mathrm{g} / \mathrm{g}$ b.w every third day) or its vehicle. Vascular reactivity was measured in the aorta as described above (a-d). The response of the aorta of intact or castrated Cyp $1 b 1^{+/+}$and $C y p 1 b 1^{-/}$ mice infused with Ang $\|$ and treated with $6 \beta-\mathrm{OHT}$ to increasing concentrations of phenylephrine (PE) and endothelin-1 (ET-1). ${ }^{*} P<0.05$ vehicle,

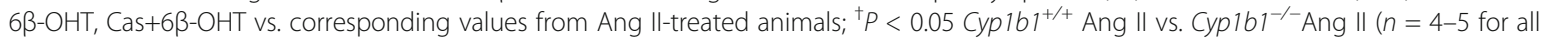
experiments, unpaired $t$ test; data are expressed as mean \pm SEM) 
or castrated $C y p 1 b 1^{+/+}$and $C y p 1 b 1^{-/-}$mice $(20 \%$ for PE and $21 \%$ and $16 \%$ for ET-1 compared to castrated

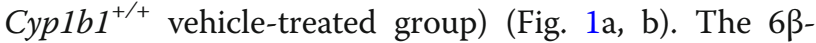
$\mathrm{OHT}$ treatment restored the magnitude of aortic constriction to PE and ET-1 in both intact Cyp $1 b 1^{-1-}(49 \%$ for PE and $94 \%$ for ET-1 compared to Cyp $1 b 1^{+/+}+6 \beta-$ $\mathrm{OHT}$ ) and castrated Cyp $1 b 1^{+/+}$and $C y p 1 b 1^{-/-}$mice (51\% and 39\% for PE, and $61 \%$ and 39\% for ET-1 compared to castrated Cyp $\left.1 b 1^{+/+} 6 \beta-O H T\right)$ infused with Ang II (Fig. 1b, c).

\section{Cyp1b1 gene disruption or castration of Cyp $1 b 1^{+/+}$mice reduced endothelial dysfunction caused by Ang II infusion, which was restored by $6 \beta-\mathrm{OHT}$}

Ang II infusion caused endothelial dysfunction in the aorta, as determined by the effect of ACh to induce maximal relaxation of the aorta pre-constricted with $\mathrm{PE}$ (54\% Cyp $1 \mathrm{b1}^{+/+}$vehicle-treated group) (Fig. 2a). However, in the intact $C y p 1 b 1^{-/-}$or castrated $C y p 1 b 1^{+/+}$and Cyp $1 b 1^{-1-}$ mice infused with Ang II, ACh- and SNPinduced relaxations of the aorta were not altered (Fig. $2 \mathrm{a}, \mathrm{b})$. The $6 \beta-\mathrm{OHT}$ treatment restored the effect of Ang II to cause endothelial dysfunction in both the intact Cyp $1 b 1^{-/-}$and castrated Cyp $1 b 1^{+/+}$and Cyp $1 b 1^{-/-}$mice (59\%, 50\%, 53\%, respectively) as determined by the loss of relaxation of the aorta by ACh (88\%) (Fig. 2c, d). SNP-induced vasodilation was not altered in these treatment groups.

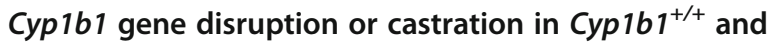
Cyp $1 b 1^{-/-}$mice reduced Ang II-induced aortic hypertrophy, which was restored by $6 \beta-\mathrm{OHT}$

Ang II infusion in Cyp $1 b 1^{+/+}$mice caused vascular hypertrophy as determined by increased media to lumen ratio of the aorta (Fig. 3a). Cyp1b1 gene disruption or castration in $C y p 1 b 1^{+/+}$and $C y p 1 b 1^{-1-}$ mice reduced this ratio (Fig. $3 \mathrm{a}$ and Fig. 4a, respectively). The $6 \beta-\mathrm{OHT}$ treatment brought back the effect of Ang II to cause aortic hyper-

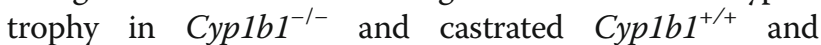
$C y p 1 b 1^{-1-}$ mice as indicated by increased media to lumen ratio of the aorta (Fig. $3 \mathrm{~b}$ and Fig. 4b, respectively).

Cyp1b1 gene disruption or castration in Cyp $1 b 1^{+/+}$and Cyp $1 b 1^{-1-}$ mice attenuated vascular fibrosis caused by Ang II, which was restored by $6 \beta-\mathrm{OHT}$

Infusion of Ang II increased vascular fibrosis, as indicated by increased collagen staining in the aorta (Fig. 5a). Cyp1b1 gene disruption or castration in Cyp $1 b 1^{+/+}$and Cyp $1 b 1^{-1-}$ mice reduced collagen accumulation (Fig. 5a and Fig. 6 a, respectively), which was restored by treatment with $6 \beta-\mathrm{OHT}$ (Fig. $5 \mathrm{~b}$ and Fig. 6b, respectively).
Cyp $1 b 1$ gene disruption or castration in $C y p 1 b 1^{+/+}$and Cyp $1 b 1^{-/-}$mice infused with Ang II attenuated ROS generation, which was restored by $6 \beta-\mathrm{OHT}$

Ang II infusion increased vascular ROS production as indicated by increased 2-hydroxyethidium fluorescence in the aorta of $C y p 1 b 1^{+/+}$, but not in the intact $C y p 1 b 1^{-/-}$or castrated $C y p 1 b 1^{+/+}$and $C y p 1 b 1^{-/-}$mice (Fig. 7a and Fig. 8a, respectively). Treatment with $6 \beta$ OHT restored the ability of Ang II to increase ROS production in the aorta of intact $C y p 1 b 1^{-/-}$or castrated Cyp $1 b 1^{+/+}$and Cyp $1 b 1^{-/-}$mice (Fig $7 \mathrm{~b}$ and Fig. 8b, respectively).

Androgen receptor antagonist flutamide reduced increase in SBP and vascular hypertrophy in castrated Cyp $1 b 1^{+/+}$ mice infused with Ang II and treated with $6 \beta-\mathrm{OHT}$ Castration in Cyp $1 b 1^{+/+}$mice reduced the Ang II-induced increase observed in SBP and aortic hypertrophy, which was restored by $6 \beta-\mathrm{OHT}$ (Fig. 9a, b, respectively). Treatment with flutamide reduced this increase in SBP and vascular hypertrophy $(P<0.05)$ (Fig. 9a, b, respectively).

\section{Discussion}

The main findings of this study are that $6 \beta-\mathrm{OHT}$, a metabolite of testosterone generated by CYP1B1, contributes to the effects of Ang II to (1) increased vascular reactivity to PE and ET-1, (2) endothelial dysfunction, (3) vascular hypertrophy, (4) vascular fibrosis, and (5) oxidative stress. Previously, we reported that Cyp $1 b 1$ gene disruption or chemical inhibition of CYP1B1 activity minimized the Ang II-induced increase in vascular reactivity to vasoconstrictor agents, increased vascular ROS production, and endothelial dysfunction [11]. Moreover, we showed that Ang II stimulates the production of $6 \beta-\mathrm{OHT}$ in $C y p 1 b 1^{+/+}$, but not $C y p 1 b 1^{-/-}$mice, and it is required (i.e., acts as a permissive factor) for Ang II-induced hypertension and associated cardiac remodeling and renal dysfunction [16, 17]. The current study assessed the contribution of $6 \beta-\mathrm{OHT}$ to the action of Ang II on alterations in the vascular function, endothelial dysfunction, hypertrophy, fibrosis, and ROS production. The results revealed that Ang II infusion for 14 days increased the response of thoracic aorta to PE and ET-1 in Cyp $1 b 1^{+/+}$mice, and these effects of Ang II were minimized in $C y p 1 b 1^{-/-}$mice, thus confirming our previous results [11]. Administration of $6 \beta-\mathrm{OHT}$ to Cyp $1 b 1^{-/-}$mice that do not generate this testosterone metabolite [16] restored the increase in the response of the thoracic aorta to PE and ET-1 in Ang II-infused intact $C y p 1 b 1^{-/-}$or castrated $C y p 1 b 1^{+/+}$and $C y p 1 b 1^{-/-}$ mice. Therefore, it appears that $6 \beta-\mathrm{OHT}$ treatment alone, which did not alter the vascular response to PE and ET-1, is necessary for the expression of the increase 

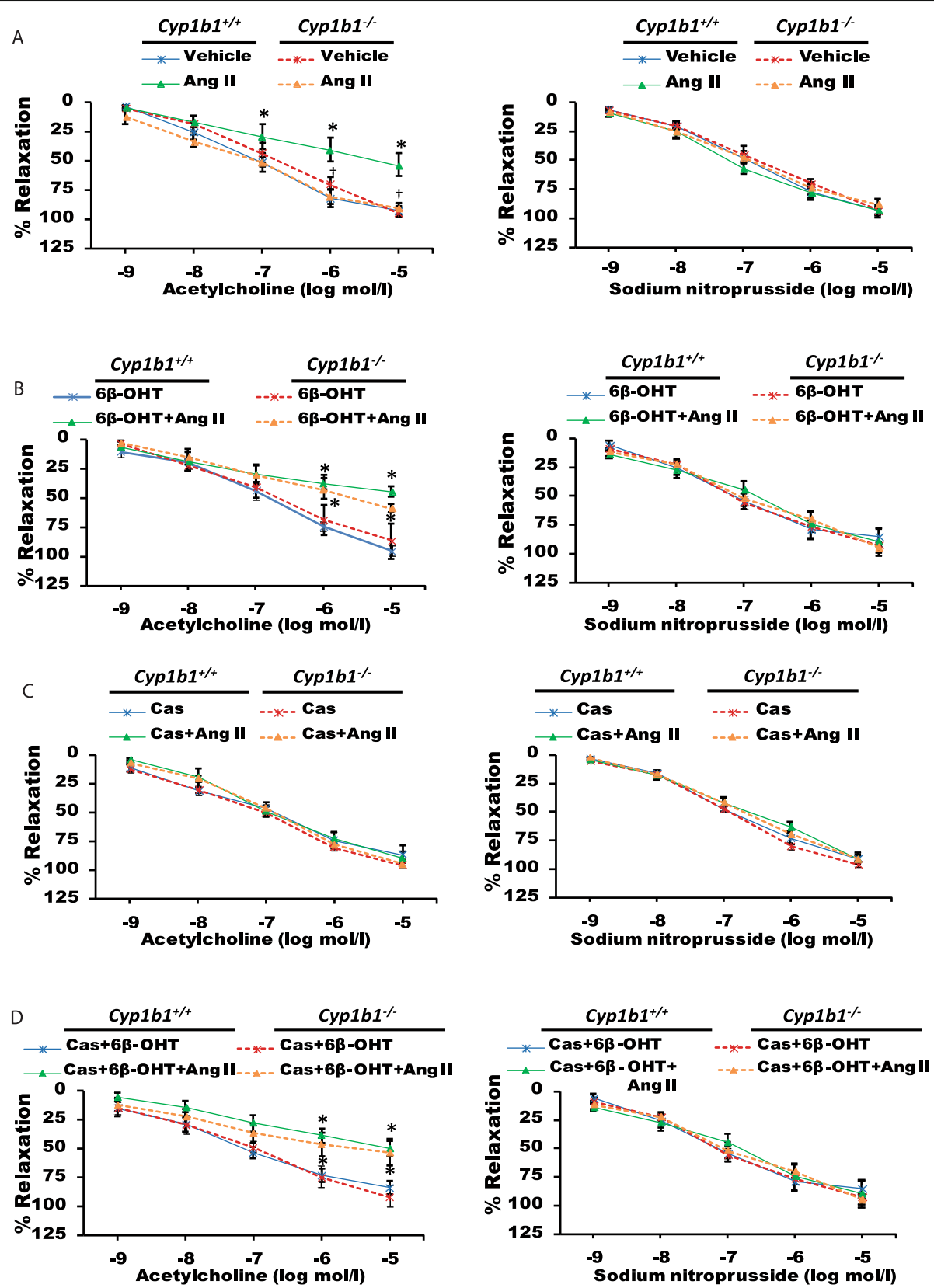

Fig. 2 Cyp 1 b1 gene disruption or castration reduced endothelial dysfunction associated with angiotensin (Ang) II-induced hypertension, which was restored by $6 \beta$-hydroxytestosterone $6 \beta-O H T$. Mice were infused with either Ang II (700 ng/kg/day) or vehicle for 14 days and given i.p. injections of $6 \beta-\mathrm{OHT}(15 \mu \mathrm{g} / \mathrm{g}$ b.w every third day) or its vehicle. Endothelial function was measured in the thoracic aorta, as described in the "Materials and methods" section (a-d). Vascular response to increasing concentrations of acetylcholine (ACh; endothelium-dependent relaxation) and sodium nitroprusside (SNP; endothelium-independent relaxation), respectively. ${ }^{*} P<0.05$ vehicle, $6 \beta-\mathrm{OHT}$, Cas $+6 \beta-\mathrm{OHT}$ vs. corresponding values from Ang II-treated animals; ${ }^{\dagger} P<0.05 \mathrm{Cyp} \mathrm{b} \mathrm{1}^{+/+}$Ang II vs. Cyp $1 \mathrm{~b} \mathrm{I}^{-1-}$ Ang II ( $n=4$ for all experiments, unpaired $t$ test; data are expressed as mean \pm SEM)

in vascular reactivity caused by Ang II infusion in the male mice.

Ang II infusion also caused endothelial dysfunction as indicated by the attenuation of relaxation to $\mathrm{ACh}$, but not to SNP in the aorta of Cyp $1 b 1^{+/+}$male mice. Cyp $1 b 1$ gene disruption minimized the effect of Ang II [16]. In the present study, we found that in Ang II-infused Cyp $1 b 1^{-/-}$mice, administration of $6 \beta-O H T$ caused endothelial dysfunction in the aorta. Infusion of Ang II also produced vascular hypertrophy as indicated by the increased media to lumen ratio of the aorta in $C y p 1 b 1^{+/+}$ mice; this effect of Ang II was abrogated in Cyp $1 b 1^{-/-}$ 

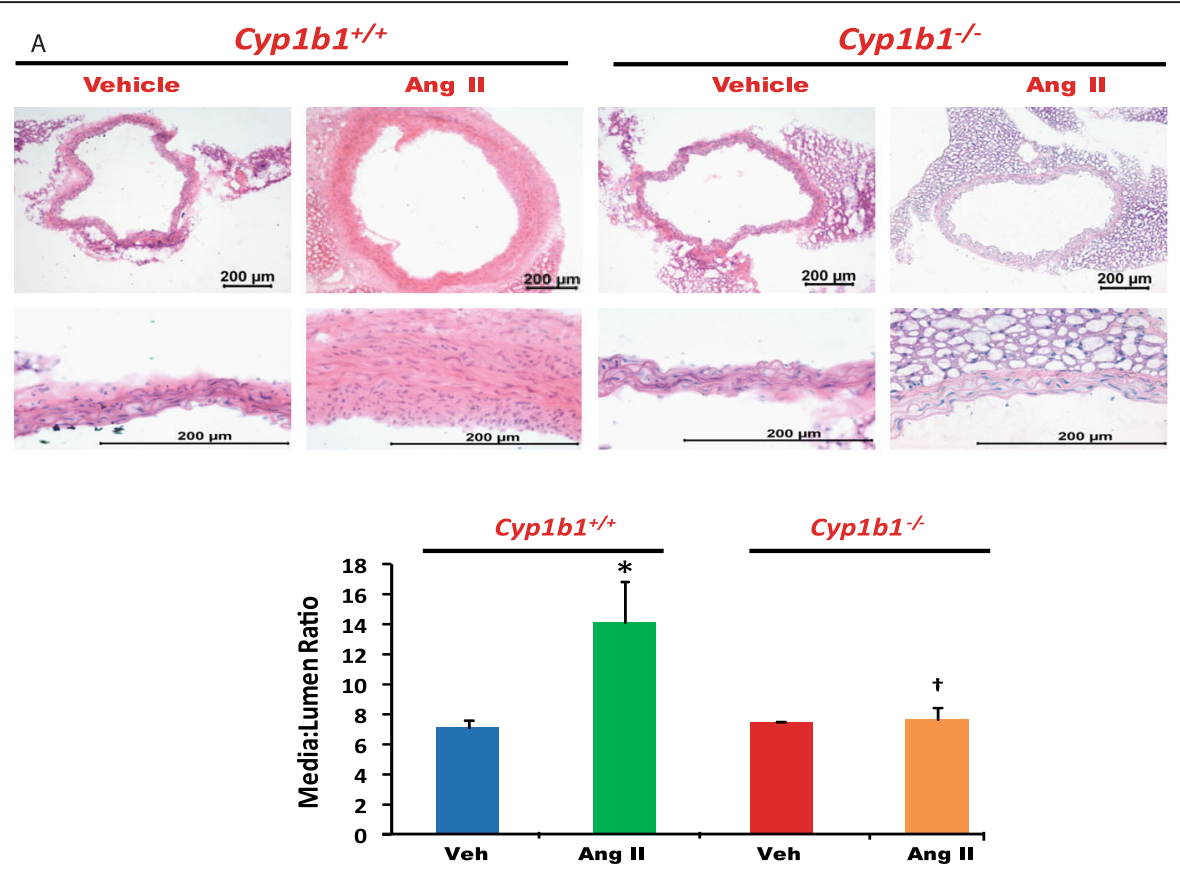

B

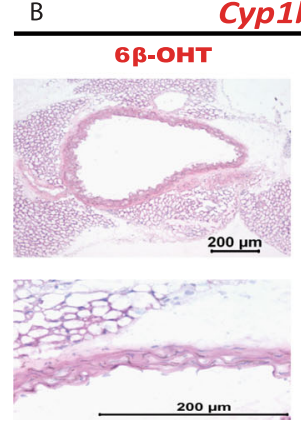

\section{yp1b1 $1^{+/+}$}
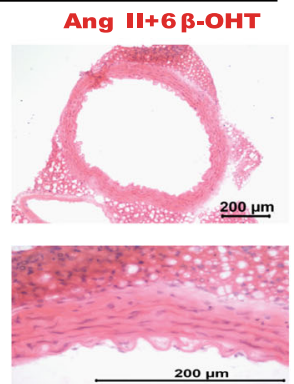

Cyp1b1+/+

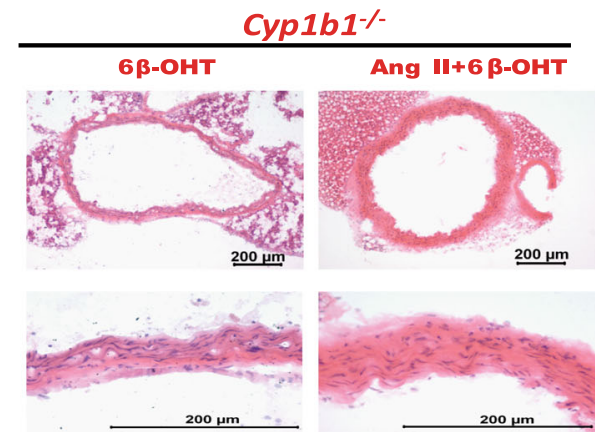

Cyp1b1\%

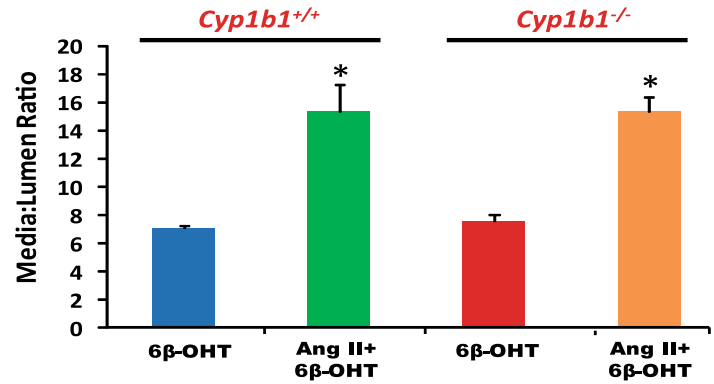

Fig. 3 Cyp 1 b1 gene disruption reduced vascular hypertrophy associated with angiotensin (Ang) II-induced hypertension, which was restored by

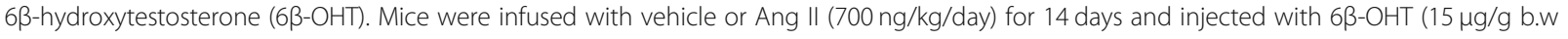
every third day) as described in the "Materials and methods" section. After Ang II infusion, the aorta was removed and processed, H\&E staining was performed, and the media/lumen ratio was calculated $(\mathbf{a}, \mathbf{b}) .{ }^{*} P<0.05$ vehicle, $6 \beta-\mathrm{OHT}$ vs. corresponding values from Ang II-treated animals;

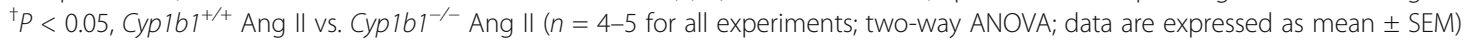

mice. However, 6 6 -OHT restored the effect of Ang II to cause vascular hypertrophy in $\mathrm{Cyp} 1 \mathrm{b1}^{-/-}$mice. $6 \mathrm{\beta}-\mathrm{OHT}$ also mediates the effect of Ang II in causing aortic fibrosis, because the Ang II-induced collagen accumulation that was abrogated in $C y \mathrm{Plb1}^{-/}$mice was significantly restored by
$6 \beta-\mathrm{OHT}$. Further, support for the role of $6 \beta-\mathrm{OHT}$ in the action of Ang II to increase vascular reactivity, endothelial dysfunction, vascular hypertrophy, and fibrosis was obtained in castrated mice. Castration attenuated the increase in vascular reactivity, endothelial dysfunction, vascular 
A

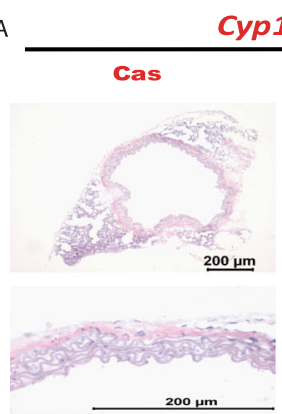

yp1b1+/+

Cas+Ang II

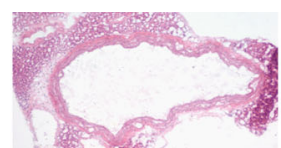

$\underline{200 \mu \mathrm{m}}$

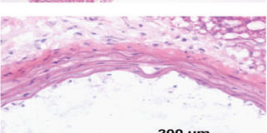

Cyp1b1/++

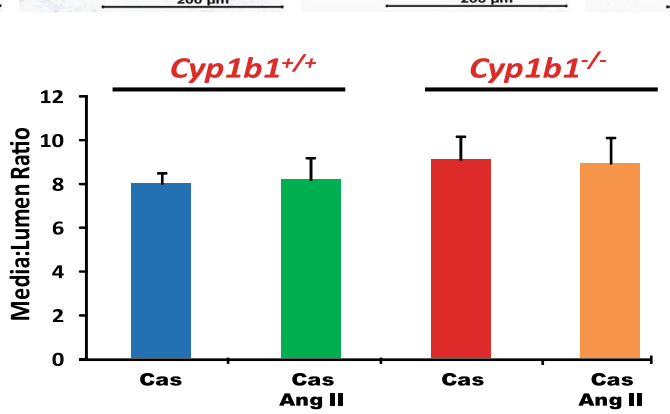

$200 \mathrm{~mm}$

\section{Cyp1b1\%-}

Cas+Ang II

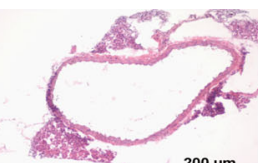

$200 \mu \mathrm{m}$
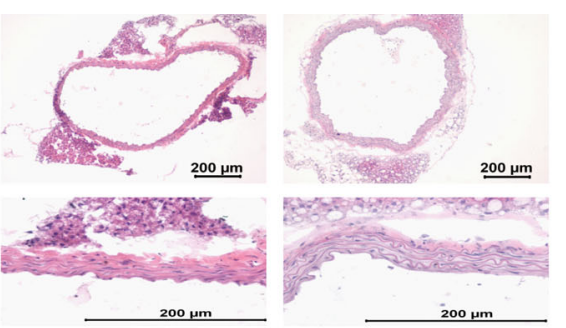

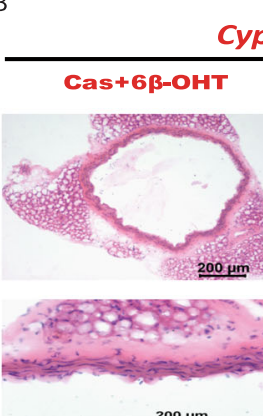

Cyp1b1+/+
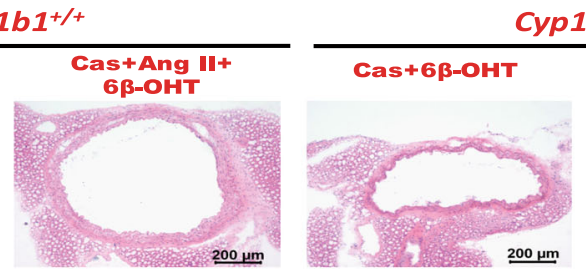

Cyp1b1\%
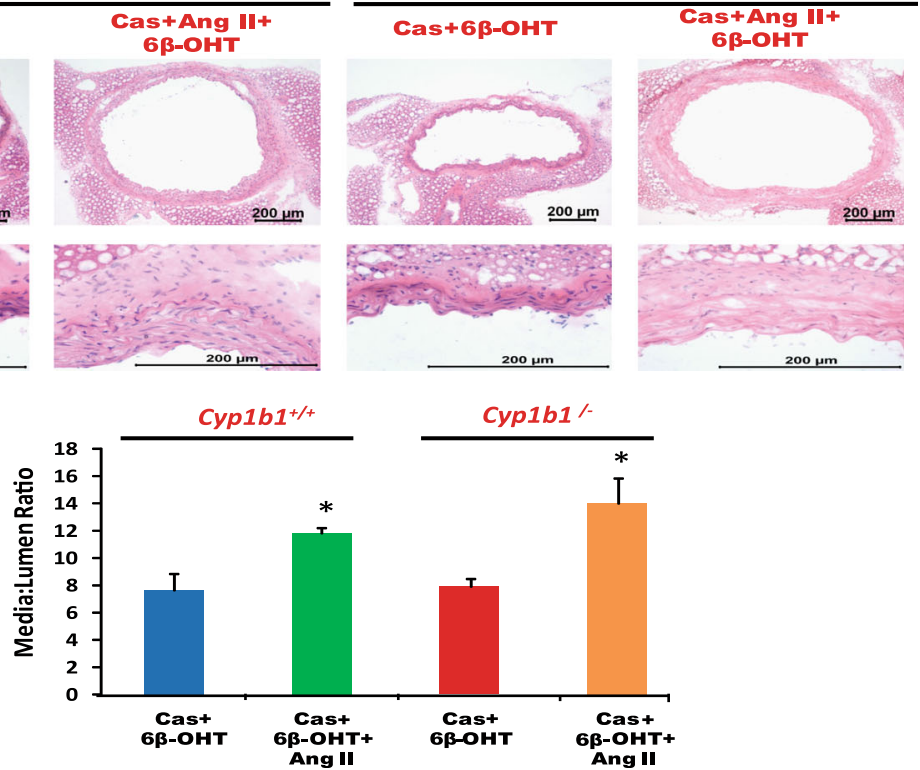

Fig. 4 Castration reduced vascular hypertrophy associated with angiotensin (Ang) Il-induced hypertension, which was restored by $6 \beta$ -

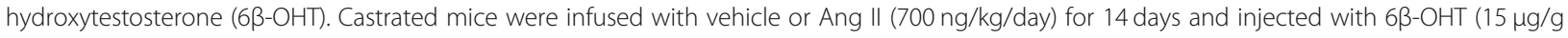
b.w every third day) as described in "Materials and methods" section. After Ang II infusion, the aorta was removed, H\&E staining was performed, and the media/lumen ratio calculated $(\mathbf{a}, \mathbf{b}) .{ }^{*} P<0.05$ Cas $+6 \beta-O H T$ vs. corresponding values from Ang II-treated animals $(n=4-5$ for all experiments; two-way ANOVA; data are expressed as mean \pm SEM)

hypertrophy, and fibrosis in Ang II-infused $\mathrm{Cyp}_{1 b 1^{+/+}}$mice. However, concurrent administration of $6 \beta-\mathrm{OHT}$ restored the effects of Ang II to increase aortic reactivity to PE and ET-1 and cause endothelial dysfunction, hypertrophy, and fibrosis in castrated $\mathrm{Cyp} \mathrm{bl}^{+/+}$mice. The mechanism by which $6 \beta-\mathrm{OHT}$ mediates the effects of Ang II to increase vascular reactivity and to cause endothelial dysfunction, hypertrophy, and aortic fibrosis in intact $C y p 1 b 1^{-/-}$and castrated Cyp $1 b 1^{+/+}$and Cyp $1 b 1^{-/-}$mice could be the consequence of the restoration of Ang II-induced increase in BP [16]. However, further studies in vitro and in vivo using hydralazine, a direct vasodilator, are required to establish the BP-dependent and BP-independent mechanism by which $6 \beta$-OHT mediates the vascular effects of Ang II. 
A

Cyp161+/+

Cyp161\%
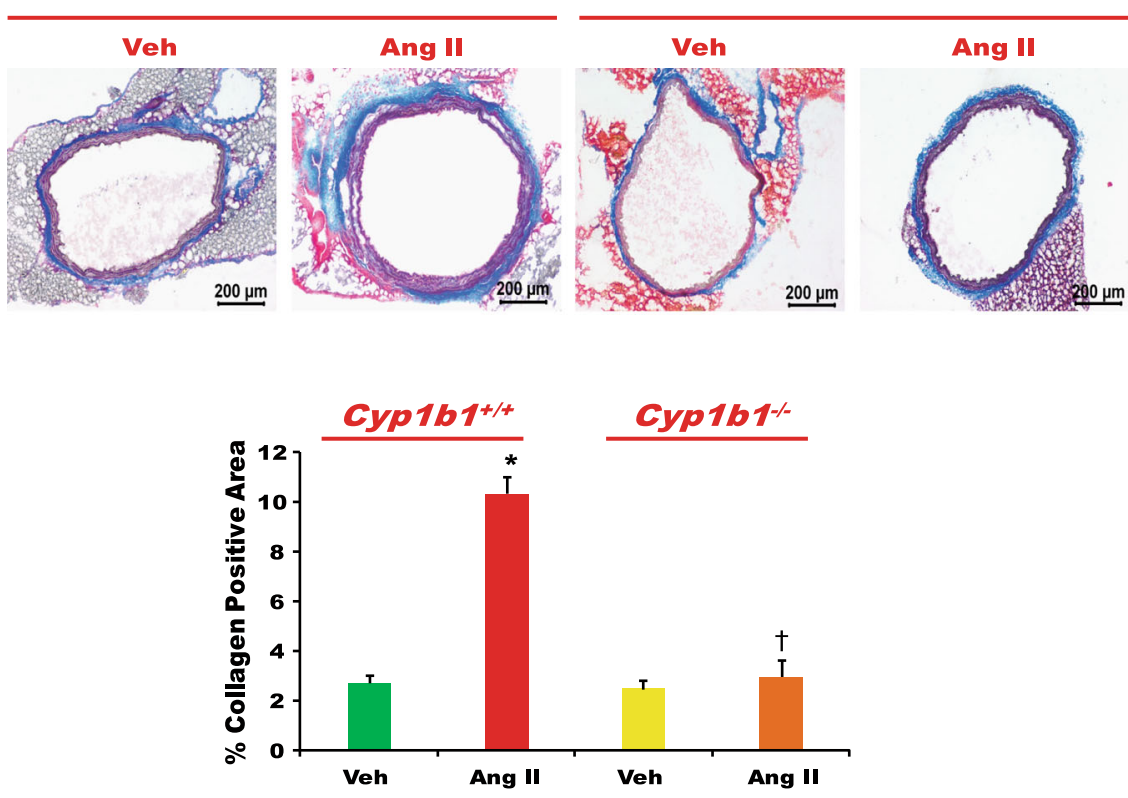

B

Cyp161+1+
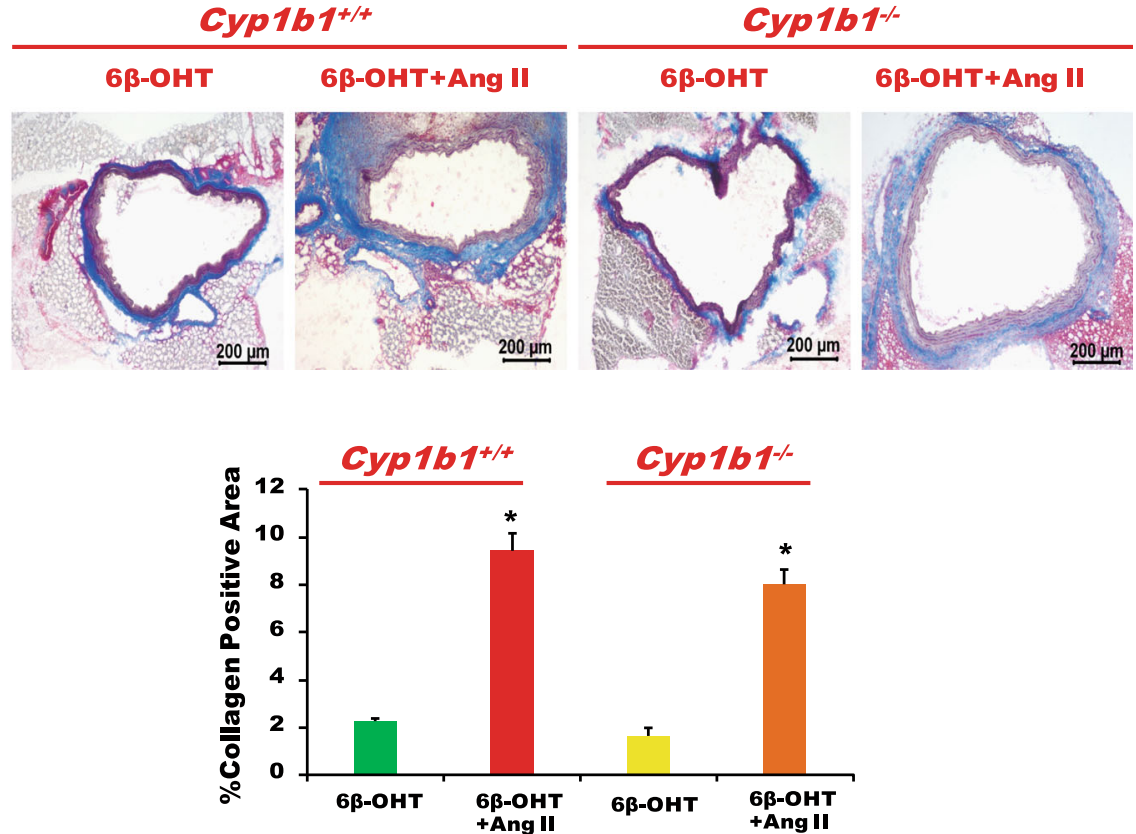

Fig. 5 Cyp 1 b1 gene disruption reduced vascular fibrosis associated with angiotensin (Ang) Il-induced hypertension, which was restored by $6 \beta-$

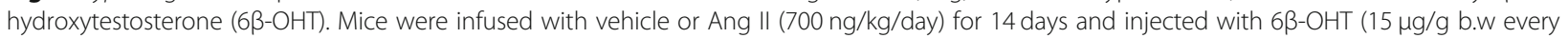
third day) as described in the "Materials and methods" section. After Ang II infusion, the aorta was removed, processed, and stained with Masson's trichrome to reveal collagen deposition $(\mathbf{a}, \mathbf{b})$. The percentage positive area for collagen staining was calculated. ${ }^{*} P<0.05$ vehicle, $6 \beta-$ OHT vs. corresponding values from Ang II-treated animals; ${ }^{\dagger} P<0.05$, Cyp $1 b 1^{+/+}$Ang II vs. Cyp $1 b 1^{-/-}$Ang II ( $n=3$ for all experiments; data are expressed as mean \pm SEM)

Ang II increases vascular ROS production in rats and mice, and renal cortex in SHR [20-22]. Cyp1b1 gene disruption and inhibition of its activity decrease vascular and renal oxidative stress in rats and mice [11-15]. Moreover, $6 \beta$-OHT was shown to mediate Ang II-induced increases in cardiac and renal oxidative stress [16-17]. Our finding that administration of $6 \beta$-OHT to the intact $C y p 1 b 1^{-/-}$or castrated $C y p 1 b 1^{+/+}$and $C y p 1 b 1^{-/-}$mice infused with Ang II increased ROS production suggests that $6 \beta-\mathrm{OHT}$ is required for the restoration of the effect of Ang II to 
A

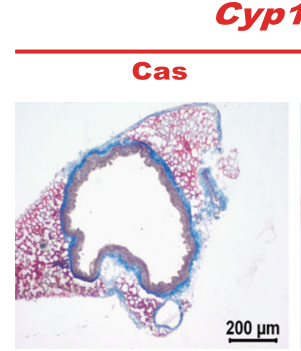

Cyp161+/+

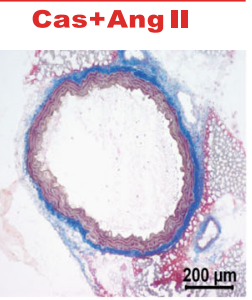

Cyp1b1\%

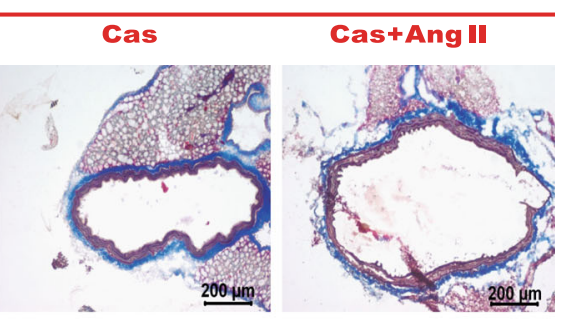

Cyp161\%

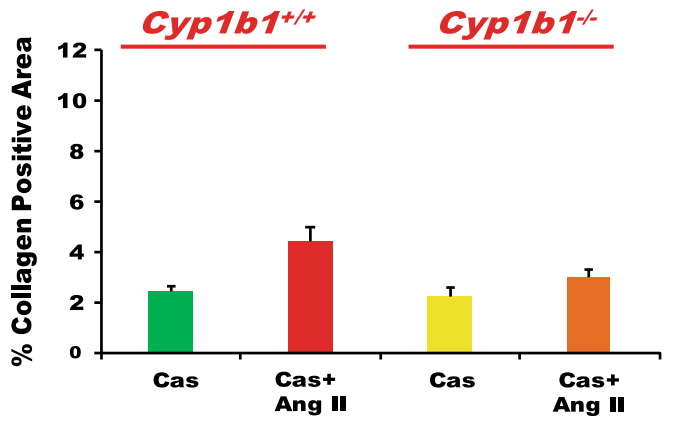

B

Cyp161+/

Cyp161\%
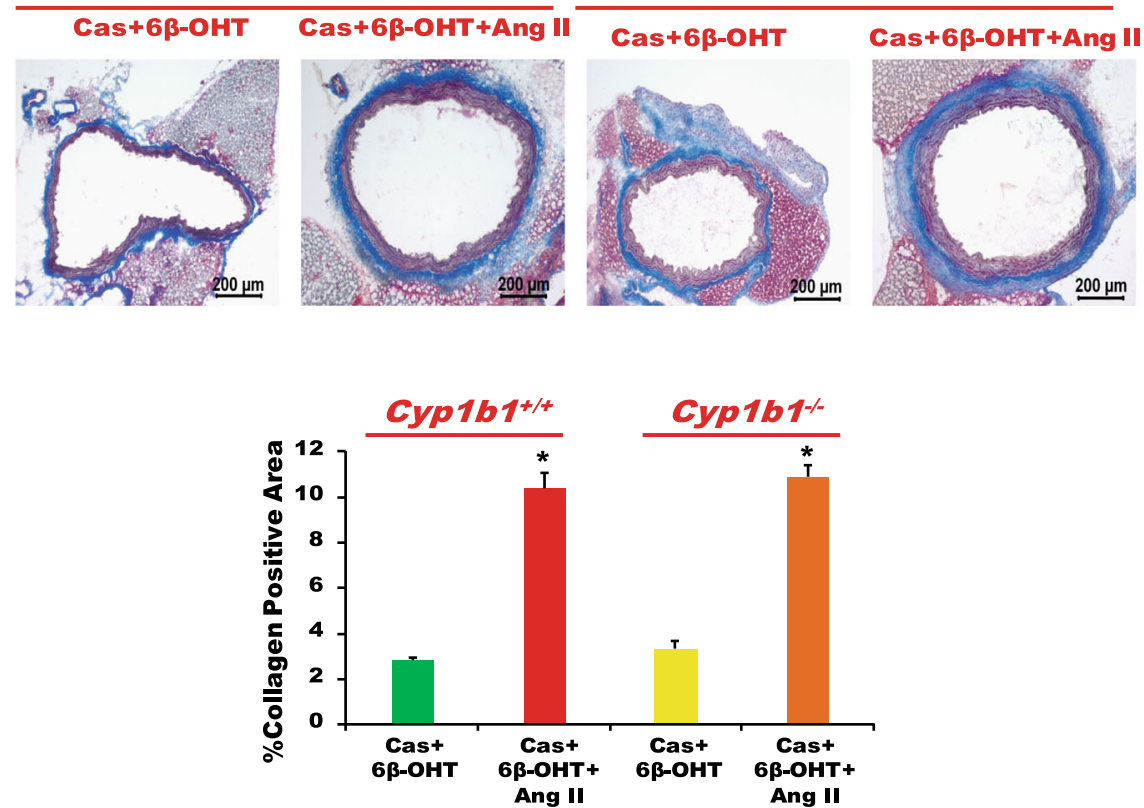

Fig. 6 Castration (Cas) mitigated angiotensin (Ang) II-induced vascular fibrosis in Cyp $161^{+/+}$mice, which was restored by $6 \beta$-hydroxytestosterone $(6 \beta-\mathrm{OHT}) . \mathrm{Cyp} 1 \mathrm{~b}^{+/+}$and $\mathrm{Cyp} 1 \mathrm{~b} 1^{-/-}$mice were castrated and infused with Ang II $(700 \mathrm{ng} / \mathrm{kg} / \mathrm{day})$ and treated with $6 \beta-\mathrm{OHT}(15 \mu \mathrm{g} / \mathrm{g}$ b.w every third day). At the end of Ang II infusion, the aortas were removed, cut into sections, and stained with Masson's trichrome staining for localization of collagen deposition $(\mathbf{a}, \mathbf{b})$. The percentage positive area for collagen staining was calculated. ${ }^{*} P<0.05$ Cas $+6 \beta$-OHT vs. corresponding values from Ang II-treated animals ( $n=3$ for all experiments, two-way ANOVA; data are expressed as mean \pm SEM)

increase oxidative stress. The endothelial dysfunction is, in part, attributed to the result of inactivation of NO by ROS [23]. Therefore, it appears that by mediating Ang IIinduced ROS production in the aorta, $6 \beta-O H T$ causes endothelial dysfunction. The increase in ROS production by Ang II infusion could result in increased vascular reactivity and hypertrophy through activation of ERK1/2 and p38 MAPK, which are known to mediate Ang IIinduced hypertrophy in cultured VSMCs [24, 25]. Previously, we reported that Ang II increased aortic ERK1/2 and p38 MAPK activity and that these effects were attenuated by treatment with the CYP1B1 inhibitor $2,3^{\prime}, 4,5^{\prime}$ - 
A

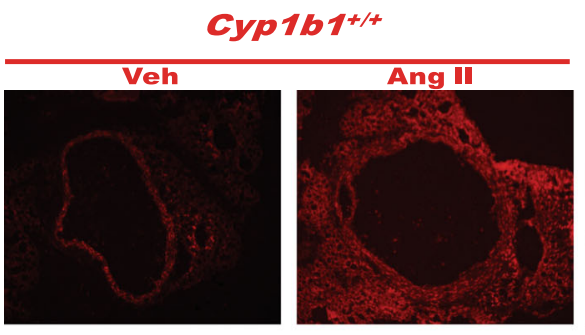

Cyp161+14
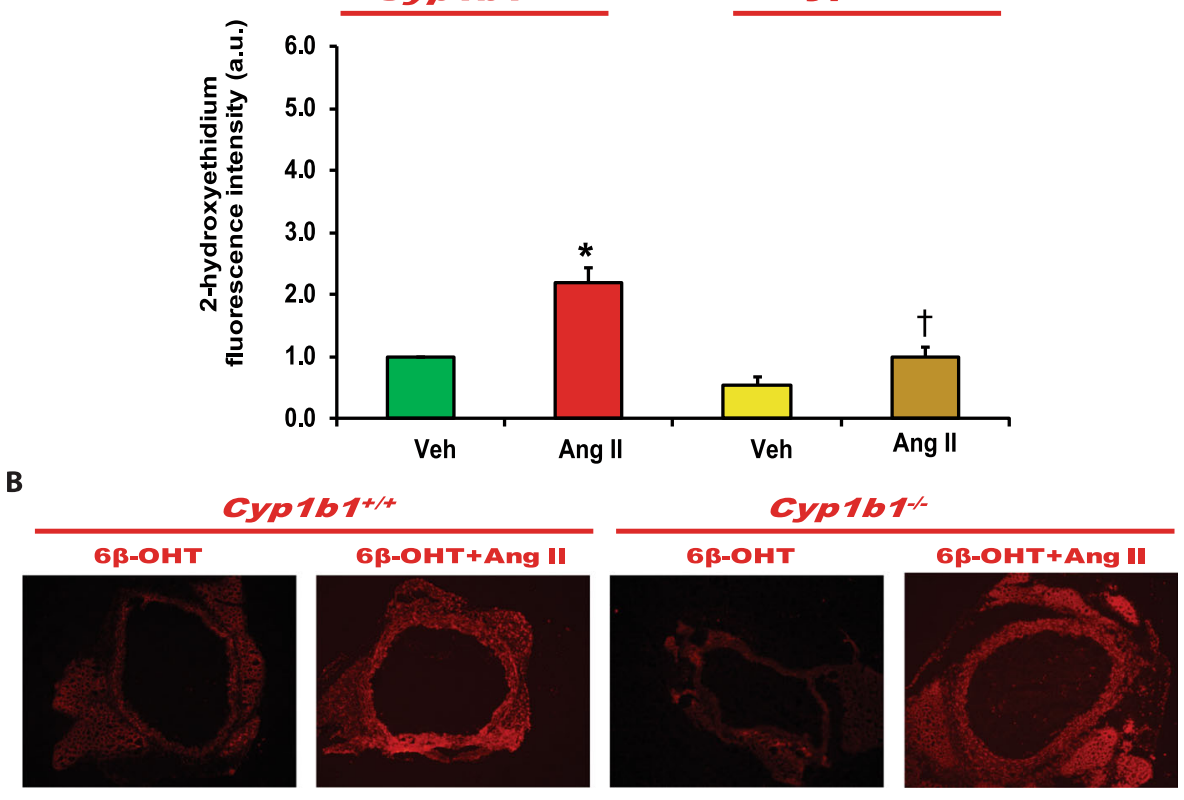

Cyp1b1-

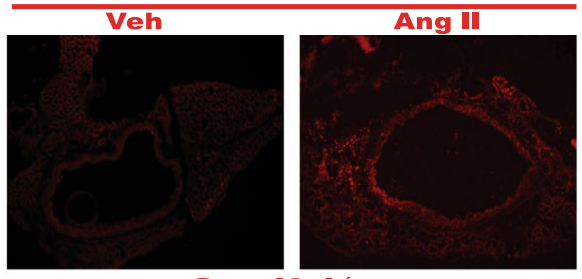

Cyp161\%

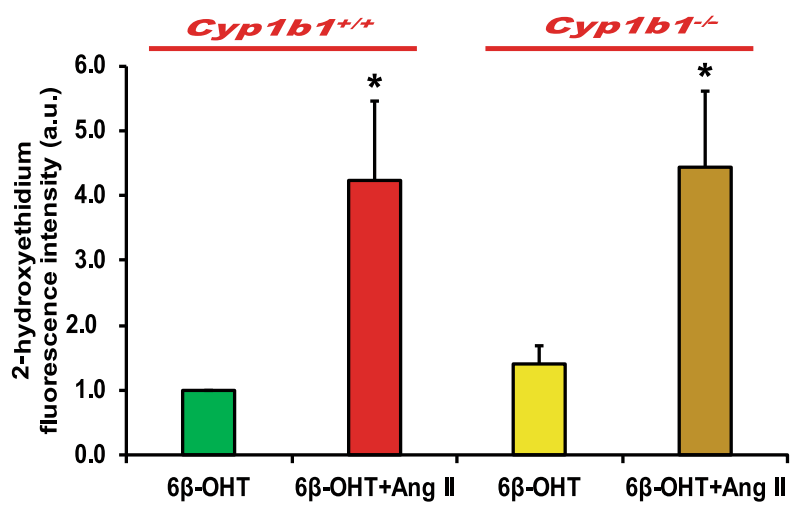

Fig. 7 Cyp 1 b1 gene disruption minimized angiotensin (Ang II)-induced superoxide production, which was reversed by 6 $\beta$-hydroxytestosterone $(6 \beta-O H T) . C y p 1 b 1^{+/+}$and Cyp $1 b 1^{-1-}$ mice were infused with vehicle or Ang II (700 ng/kg/day) (upper panel) and treated with $6 \beta-O H T$ (15 $\mu$ g/g b.W every third day) or $6 \beta-\mathrm{OHT}+$ Ang $\|$ (lower panel) for 14 days. Aortic superoxide production was determined by the fluorescence intensity of $2-$ hydoxyethidium $(\mathbf{a}, \mathbf{b})$. Photomicrographs are representative of the aorta from mice in each of the different treatment groups following incubation with dihydroethidium. The graph depicts the quantified data. ${ }^{*} P<0.05$ vehicle, $6 \beta$-OHT vs. corresponding value from Ang II-treated

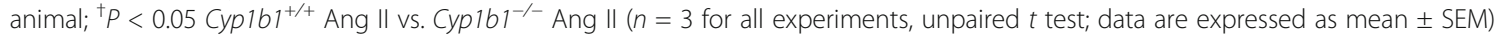

tetramethoxystilbene [11]. Moreover, 2,3',4,5' -tetramethoxystilbene in cultured rat VSMCs or cells transduced with adenovirus CYP1B1 short hairpin RNA, Ang II- and arachidonic acid-induced increase in ERK1/2 and p38 MAPK activities were inhibited without alterations in the expression of Ang II type 1 receptor or its coupling to G proteins [26].

CYP1B1 gene disruption did not alter the expression of $\mathrm{AT} 1$ receptor, $\mathrm{ACE}$, or Mas receptor in the heart or kidney of mice infused with Ang II [16, 17]. However, 
A

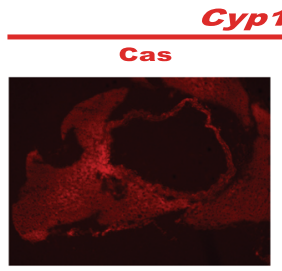

Cyp161+1+
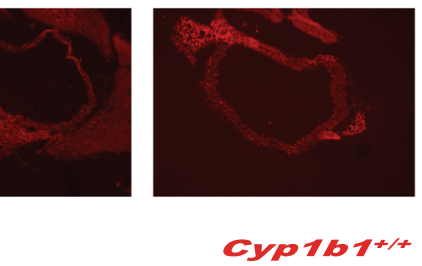

Cyp161+1t
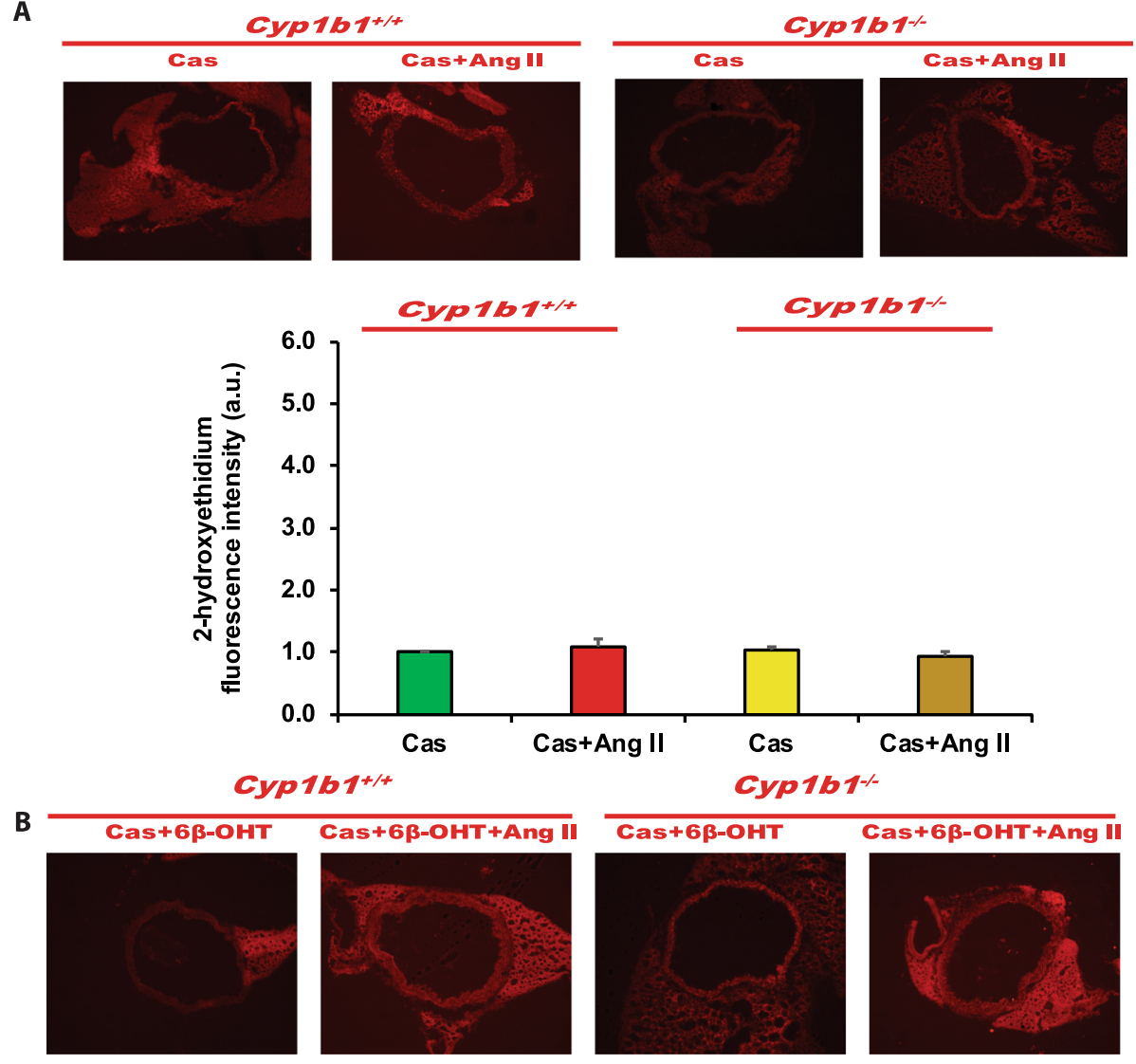

Cyp161\%
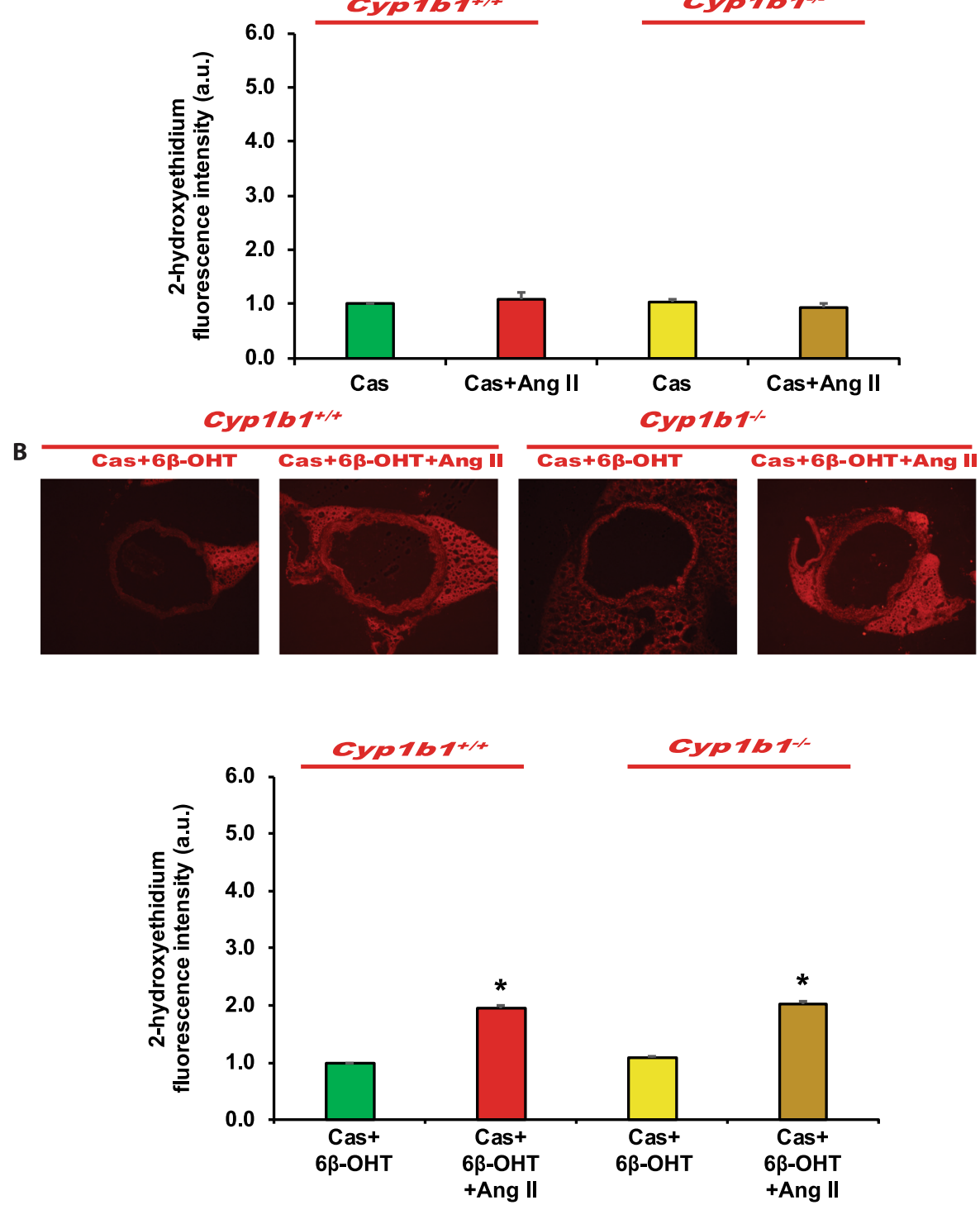

Fig. 8 6B-Hydroxytestosterone (6ß-OHT) restored angiotensin (Ang) Il-induced superoxide production that was minimized in castrated (Cas) Cyp $1 b 1^{+/+}$and $C y p 1 b 1^{-1-}$ mice. Cyp $1 b 1^{+/+}$and $C y p 1 b 1^{-/-}$mice were castrated and then infused with vehicle or Ang II (700 ng/kg/day) (upper panel) and treated with $6 \beta-\mathrm{OHT}(15 \mu \mathrm{g} / \mathrm{g}$ b.w every third day) or $6 \beta-\mathrm{OHT}+$ Ang $I I$ (lower panel) for 14 days. a Aortic superoxide production was determined by the fluorescence intensity of 2-hydoxyethidium. $\mathbf{a}, \mathbf{b}$ Photomicrographs are representative of the aorta from mice in each of the different treatment groups following incubation with dihydroethidium. $\mathbf{b}$ The graph depicts the quantified data. ${ }^{*} P<0.05$ vehicle vs.

corresponding values from Ang II-treated animals ( $n=3$ for all experiments, unpaired $t$ test, and the data are expressed as mean \pm SEM)

the expression of AT1 receptor and ACE in the kidney was reduced by castration in $C y p 1 b 1^{+/+}$and $C y p 1 b 1^{-/-}$ mice, and it was reversed and enhanced by treatment with $6 \beta$-OHT. Whether $6 \beta-\mathrm{OHT}$ increases the aortic expression of AT1 receptor and ACE that contributes to the effect of Ang II to increase vascular reactivity and cause endothelial dysfunction, hypertrophy, aortic fibrosis, and ROS production remains to be determined. 

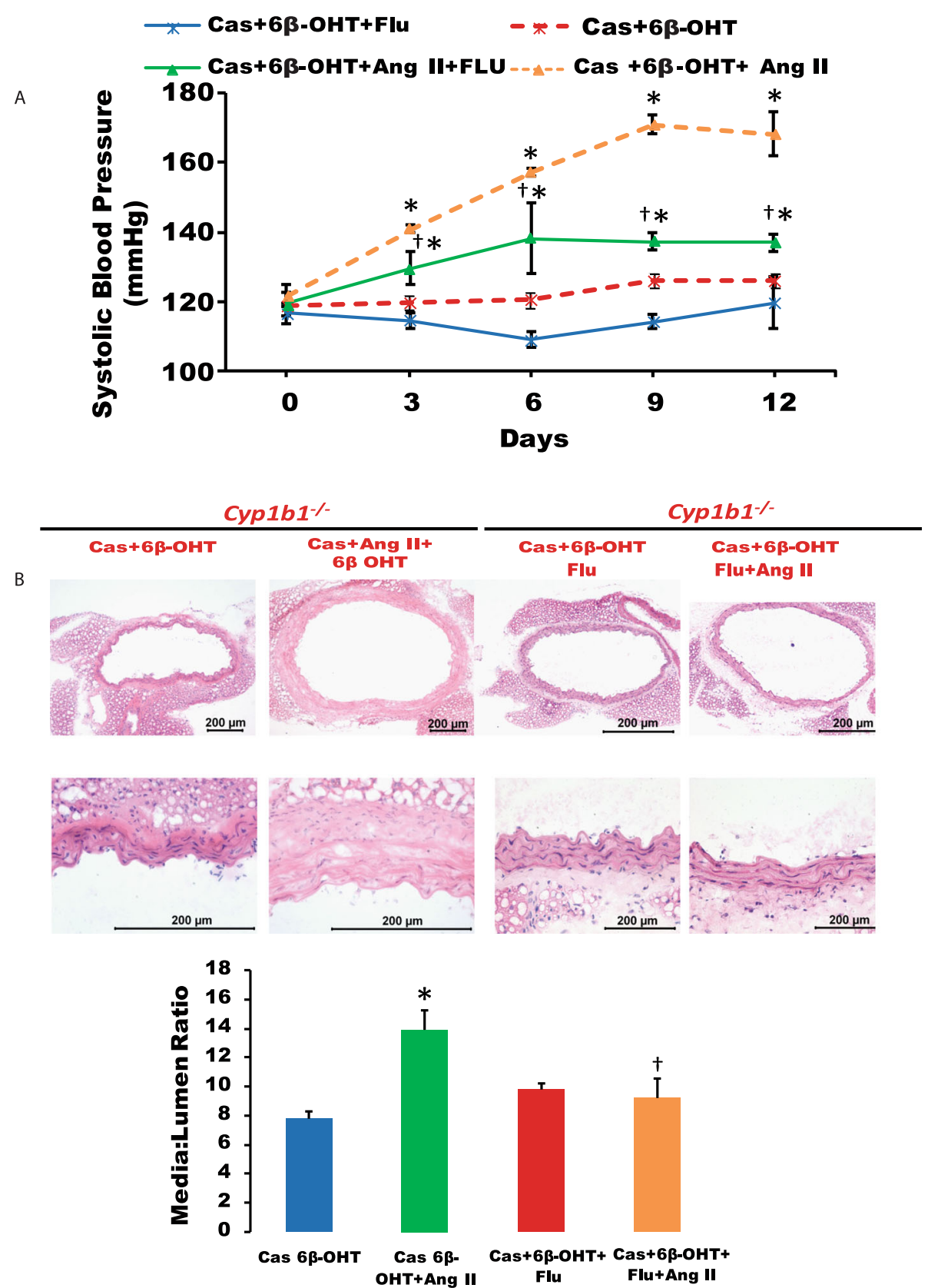

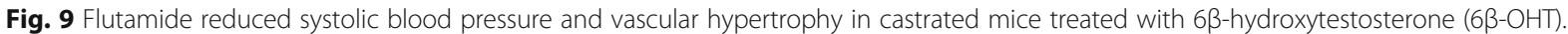
Castrated Cyp $1 b^{+/++}$mice were infused with vehicle or angiotensin (Ang) II (700 ng/kg/day) and treated with $6 \beta-O H T(15 \mu \mathrm{gg} / \mathrm{g}$ b.w every third day) and flutamide (FLU) $(8 \mathrm{mg} / \mathrm{kg}$ every day), and blood pressure was measured (a). H\&E staining was performed to determine vascular hypertrophy, and the media to lumen ratio was calculated (b). The graph depicts the quantified data. ${ }^{*} P<0.05$ Cas $+6 \beta-O H T$, Cas $+6 \beta-O H T+F L U$ vs. corresponding values from Ang II-treated animals; ${ }^{\dagger} P<0.05$ Cas $+6 \beta-O H T+F L U+A n g ~ \|$ vs. Cas $+6 \beta-O H T+$ Ang $\|(n=5$ for all experiments, twoway ANOVA; data are expressed as mean \pm SEM)

Administration of the androgen receptor blocker flutamide either peripherally or centrally reduced the increase in BP observed in Ang II-infused mice and in transgenic hypertensive TGR(mREN2) rats (TGR) harboring the murine Ren-2 gene [9, 27-28]. Flutamide also prevented endothelial dysfunction and an increase in vascular reactivity in diabetic Zucker rats and Ang IIinfused mice [29-32]. In the present study, the effect of $6 \beta-\mathrm{OHT}$ to restore the Ang II-induced increase in BP and aortic hypertrophy that was reduced by castration in Cyp $1 b 1^{+/+}$mice was inhibited by flutamide. This is the first evidence suggesting that $6 \beta-\mathrm{OHT}$ contributes to the 
effect of Ang II on BP and hypertrophy via the androgen receptor. However, further studies are required to determine if it involves the DNA- or non-DNA-dependent androgen receptor or G-protein coupled androgen receptor (GPRC6A) [33]. Moreover, the effect of flutamide on the $6 \beta-\mathrm{OH}$-mediated effect of Ang II to increase vascular reactivity and produce endothelial dysfunction also needs to be examined. Testosterone has been reported to downregulate the expression of the AT2 receptor via the androgen receptor-mediated ERK1/2 MAP kinase pathway in rat aorta [34]. Whether $6 \beta$-OHT mediates the vascular effects of Ang II by downregulating AT2 receptors in the mice aorta remains to be explored.

\section{Perspectives and significance}

This study provides evidence that $6 \beta-\mathrm{OHT}$, a metabolite of testosterone generated by CYP1B1, acts as a permissive factor that contributes to the effects of Ang II to increase vascular reactivity; cause endothelial dysfunction, vascular hypertrophy, and fibrosis; and increase oxidative stress in male mice. Moreover, the effect of $6 \beta-\mathrm{OHT}$ on Ang IIinduced increases in BP and aortic hypertrophy is mediated by the androgen receptor. In contrast to male mice, we have shown that Ang II produces a lower increase in BP in Cyp $1 b 1^{+/+}$as compared to Cyp $1 b 1^{-/-}$female mice [11]. This diminished ability of Ang II to increase BP in female Cyp $1 \mathrm{bl}^{+/+}$mice is associated with decreased cardiac and vascular smooth muscle remodeling, reduced endothelial dysfunction, and decreased vascular reactivity to $\mathrm{PE}$ and ET-1 [11]. Protection against the increase in vascular reactivity, endothelial dysfunction, and ROS production associated with hypertension in female mice was found to be due to the CYP1B1-17 $\beta$-estradiol generated metabolite 2methoxyestradiol [13]. Therefore, CYP1B1 could serve as a novel target for developing agents that inhibit CYP1B1 for treating the increased vascular reactivity, endothelial dysfunction, vascular hypertrophy, fibrosis, and ROS production associated with Ang II- and testosterone-dependent hypertension in males, but inhibitors of CYP1B1 could be detrimental in treating vascular changes associated with hypertension in females.

\section{Acknowledgements}

We thank Dr. Amanda Susan Clarke, Director, Office of Scientific Writing, Office of the Vice Chancellor for Research, University of Tennessee, Health Science Center, Memphis, TN, for editing this manuscript.

\section{Authors' contributions}

AP helped in the design of the study, conducted experiments, performed analysis, contributed to interpretation of the data, and drafted the manuscript. BJ designed the study elements, performed the experiments, analyzed the data, and revised the manuscript. KM provided technical assistance in histology and edited the manuscript. WA provided technical support. FG provided the Cyp $161^{-1-}$ mice and reviewed the manuscript. KUM conceived and coordinated the study, contributed to the design of experiments and analysis and interpretation of the data, and assisted in drafting and editing the manuscript. All authors read, edited, and approved the final manuscript.

\section{Funding}

This work was supported by the National Institutes of Health, National Heart, Lung, and Blood Institute grants R01HL-19134-41 and R01HL-079109-09 and a UTHSC CORNET award.

\section{Availability of data and materials}

The data supporting the findings of our manuscript are available upon reasonable request by email to the corresponding author.

\section{Ethics approval and consent to participate}

Approved by the Institutional Animal Care and Use Committee at the University of Tennessee Health Science Center, Memphis, TN

\section{Consent for publication}

All the authors have read the manuscript and consented for publication.

\section{Competing interests}

The authors declare that they have no competing interests.

\section{Author details}

${ }^{1}$ Department of Pharmacology, College of Medicine, University of Tennessee Health Science Center, 71 S. Manassas TSRB, Memphis, TN 38103, USA.

${ }^{2}$ Laboratory of Metabolism, National Cancer Institute, Bethesda, MD 20892, USA.

Received: 22 July 2019 Accepted: 31 December 2019

Published online: 16 January 2020

\section{References}

1. Messerli FH, Garavaglia GE, Schmieder RE, Sundgaard-Riise K, Nunez BD, Amodeo C. Disparate cardiovascular findings in men and women with essential hypertension. Ann Intern Med. 1987;107:158-61.

2. Stampfer MJ, Colditz GA, Willett WC, Manson JE, Rosner B, Speizer FE, Hennekens $\mathrm{CH}$. Postmenopausal estrogen therapy and cardiovascular disease. Ten-year follow-up from the nurses' health study. N Engl J Med. 1991;325:756-62. https://doi.org/10.1056/NEJM199109123251102.

3. Burt VL, Whelton P, Roccella EJ, Brown C, Cutler JA, Higgins M, Horan MJ, Labarthe D. Prevalence of hypertension in the US adult population. Results from the Third National Health and Nutrition Examination Survey, 19881991. Hypertension. 1995;25:305-13.

4. Staessen J, Bulpitt CJ, Fagard R, Lijnen P, Amery A. The influence of menopause on blood pressure. J Hum Hypertens. 1989;3:427-433.PMID: 2607517

5. Sandberg $\mathrm{K}$ and Ji H. Sex differences in primary hypertension. Biol Sex Differ. 2012; 3:7-1-21.doi: https://doi.org/10.1186/2042-6410-3-7.

6. Crofton JT, Ota M, Share L. Role of vasopressin, the renin-angiotensin system, and sex in Dahl salt-sensitive hypertension. J Hypertens. 1993;11: 1031-103.

7. Rowland NE, Fregly MJ. Role of gonadal hormones in hypertension in the Dahl salt-sensitive rat. Clin Exp Hypertens A. 1992;14:367-75.

8. Reckelhoff JF, Zhang H, Granger JP. Testosterone exacerbates hypertension and reduces pressure-natriuresis in male spontaneously hypertensive rats. Hypertension. 1998;31:435-9.

9. Reckelhoff JF, Zhang H, Srivastava K, Granger JP. Gender differences in hypertension in spontaneously hypertensive rats: role of androgens and androgen receptor. Hypertension. 1999;34:920-3.

10. Xue B, Pamidimukkala J, Hay M. Sex differences in the development of angiotensin II-induced hypertension in conscious mice. Am J Physiol Heart Circ Physiol. 2005;288:H2177-84.

11. Jennings BL, George LW, Pingili AK, Khan NS, Estes AM, Fang XR, Gonzalez FJ, Malik KU. Estrogen metabolism by cytochrome P450 1B1 modulates the hypertensive effect of angiotensin II in female mice. Hypertension. 2014;64: 134-49.

12. Jennings BL, Moore JA, Pingili AK, Estes AM, Fang XR, Kanu A, Gonzalez FJ, Malik KU. Disruption of the cytochrome P-450 1B1 gene exacerbates renal dysfunction and damage associated with angiotensin II-induced hypertension in female mice. 2015; F981-F992,

13. Pingili AK, Davidge KN, Thirunavukkarasu S, Khan NS, Katsurada A, Majid DSA, Gonzalez FJ, Navar LG, Malik KU. 2-Methoxyestradiol reduces angiotensin I-induced hypertension and renal dysfunction in ovariectomized female and intact male mice. Hypertension. 2017;6:1104-12. 
14. Jennings BL, Sahan-Firat S, Estes AM, Das K, Farjana N, Fang XR, Gonzalez FJ, Malik KU. Cytochrome P 450 1B1 contributes to angiotensin II-induced hypertension associated pathophysiology. Am J Physiol Hypertension. 2010; 56:667-74.

15. Jennings BL, Anderson LJ, Estes AM, Yaghini FA, Fang XR, Porter J, Gonzalez FJ, Campbell WB, Malik KU. Cytochrome P450 1B1 contributes to renal dysfunction and damage caused by angiotensin II in mice. Hypertension. 2012;59:348-54.

16. Pingili AK, Kara M, Khan NS, Estes AM, Lin Z, Li W, Gonzalez FJ, Malik KU. $6 \beta$ hydroxytestosterone, a cytochrome P450 1B1 metabolite of testosterone, contributes to angiotensin II-induced hypertension and its pathogenesis in male mice. Hypertension. 2015;65:1279-87.

17. Pingili AK, Shyamala T, Kara M, Khan NS, Brand Brand DD, Katsurada A, Majid DS, Navar LG, Gonzalez FJ, Malik KU. 6ß-Hydroxytestosterone, a cytochrome P450 1B1-testosterone-metabolite, mediates angiotensin II-induced renal dysfunction in male mice. Hypertension. 2016;67:916-26.

18. Rosendorff C. The renin-angiotensin system and vascular hypertrophy. J Am Coll Cardiol. 1996:4:803-12.

19. Buters JTM, Sakai S, Richter T, Pineau T, Alexander DL, Savas U, Doehmer J, Ward JM, Jefcoate CR, Gonzalez FJ. Cytochrome P450 CYP1B1 determines susceptibility to 7,12-dimethyl[a]anthracene-induced lymphomas. Proc Natl Acad Sci U S A. 1999;96:1977-82.

20. Rajagopalan S, Kurz S, Münzel T, Tarpey M, Freeman BA, Griendling KK, Harrison DG. Angiotensin I-mediated hypertension in the rat increases vascular superoxide production via membrane NADH/NADPH oxidase activation. Contribution to alterations of vasomotor tone. J Clin Invest. 1996; 97:1916-23.

21. Virdis A, Neves MF, Amiri F, Touyz RM, Schiffrin EL. Role of NAD(P)H oxidase on vascular alterations in angiotensin II-infused mice. J Hypertens. 2004;22: 535-42.

22. Bhatia K, Elmarakby AA, El-Remessy AB, El-Remessey A, Sullivan JC. Oxidative stress contributes to sex differences in angiotensin II-mediated hypertension in spontaneously hypertensive rats. Am J Phys Regul Integr Comp Phys. 2012;302:R274-82.

23. Sarr M, Chataigneau M, Martins S, Schott C, El Bedoui J, Oak M-H, Muller B, Chataigneau T, Schini-Kerth VB. Red wine polyphenols prevent angiotensin I-induced hypertension and endothelial dysfunction in rats: role of NADPH oxidase. Cardiovasc Res. 2006;71:794-802.

24. Reddy MA, Thimmalapura P-R, Lanting L, Nadler JL, Fatima S, Natarajan R. The oxidized lipid and lipoxygenase product 12(S)-hydroxyeicosatetraenoic acid induces hypertrophy and fibronectin transcription in vascular smooth muscle cells via p38 MAPK and CAMP response element-binding protein activation: mediation of angiotensin II effects. J Biol Chem. 2002;277:9920-8.

25. El Mabrouk M, Touyz RM, Schiffrin EL. Differential ANG II-induced growth activation pathways in mesenteric artery smooth muscle cells from SHR. Am J Physiol Heart Circ Physiol. 2001;281:H30-9.

26. Yaghini FA, Song CY, Lavrentyev EN, Ghafoor HUB, Fang XR, Estes AM, Campbell WB, Malik KU. Angiotensin I-induced vascular smooth muscle cell migration and growth are mediated by cytochrome P450 1B1-dependent superoxide generation. Hypertension. 2010;55:1461-7.

27. Gangula PR, Reed L, Yallampalli C. Antihypertensive effects of flutamide in rats that are exposed to a low-protein diet in utero. Am J Obstet Gynecol. 2005;192:952-60.

28. Baltatu O, Cayla C, lliescu R, Andreev D, Bader M. Abolition of end-organ damage by antiandrogen treatment in female hypertensive transgenic rats. Hypertension. 2003;41(3):830-3.

29. Ajayi AA, Fidelis P. The effect of flutamide on systemic and renal hemodynamics in Zucker diabetic rats: paradoxic renal vasodilator response to endothelin-1 and TXA2 receptor activation in female sex. Cardiovasc Pharmacol. 2006;48:191-8.

30. Sathishkumar K, Balakrishnan MP, Chandrasekhar Y. Enhanced mesenteric arterial responsiveness to angiotensin $\|$ is androgen receptor-dependent in prenatally protein-restricted adult female rat offspring. Biol Reprod. 2015;55: 1-6. https://doi.org/10.1095/biolreprod.114.126482.

31. Ba ZF, Wang P, Kuebler JF, Rue LW 3rd, Bland KI, Chaudry IH. Flutamide induces relaxation in large and small blood vessels. Arch Surg. 2002;137:1180-6.

32. Ba ZF, Wang P, Koo DJ, Ornan DA, Bland Kl, Chaudry $\mathbb{H}$. Attenuation of vascular endothelial dysfunction by testosterone receptor blockade after trauma and hemorrhagic shock. Arch Surg. 2001;136:1158-63.

33. Davey RA, Grossmann M. Andrigen receptor function and biology: From Bench to bedside. Clin Biochem Rev 2016;37: 3-15. PMID:27057074
34. Mishra JS, Hankins, GD, Kumar S. Journal of the Renin-AngiotensinAldosterone System (2016) DOl: https://doi.org/10.1177/1470320316674875.

\section{Publisher's Note}

Springer Nature remains neutral with regard to jurisdictional claims in published maps and institutional affiliations.
Ready to submit your research? Choose BMC and benefit from:

- fast, convenient online submission

- thorough peer review by experienced researchers in your field

- rapid publication on acceptance

- support for research data, including large and complex data types

- gold Open Access which fosters wider collaboration and increased citations

- maximum visibility for your research: over $100 \mathrm{M}$ website views per year

At BMC, research is always in progress.

Learn more biomedcentral.com/submissions 